\title{
Insuring College Failure Risk
}

\author{
Satyajit Chatterjee \\ Federal Reserve Bank of Philadelphia \\ Felicia Ionescu \\ Colgate University
}

February 15, 2008

\begin{abstract}
Under current law, participants in (college) student loan program must repay their loan in full regardless of whether they complete college. Dropout rate among college students from low-income background is anywhere between 33 to 50 percent. The combination of lack of family resources, unconstrained access to student loans and high dropout rates means that for a substantial fraction of low-income students the attempt to acquire a college degree ends in low earnings and high indebtedness. In this paper we examine whether the student loan program can gainfully offer insurance against college failure risk. We argue that such an insurance scheme is administratively feasible and provide conditions under which such insurance can be gainfully offered taking into account the constraints imposed by moral hazard. We show that the provision of such insurance will raise enrollment rates, dropout rates, and average welfare. The model is calibrated to US data on college costs, enrollment rates, college premium, and average indebtedness of program participants. Insurance against college failure risk raises enrollment rates by 4 percent, decreases college completion rate from 61 percent to 40 percent and increases welfare by about 0.24 percent.
\end{abstract}

\section{Introduction}

Recent research in the education literature provides support for the fact that financial constraints during college-going years are not crucial for college enrollment (Carneiro and Heckman 
(2002), Cameron and Taber (2001)). Rather, it is student's characteristics such as learning ability that determine their decision to enroll. Ionescu (2007) finds that given the generosity of the student loan program, funds are ready available and eligible high school graduates decide to invest in college if their returns to college education are high enough to pay for the forgone earnings for college years.

This does not mean, however, that people's college enrollment decisions are necessarily socially optimal. There is considerable financial risk in taking out a student loan to pay for college. For instance, using the 1990 PSID, Restuccia and Urrutia (2004) document that 50 percent of people who enroll in college drop out. Similarly, using the NCES data and surveys, we find that 36.8 percent and 35.2 percent of students enrolled in 1989-90 and 199596, respectively, do not possess a degree and are not enrolled five years after their initial enrollment. For these people, the foregone earnings and out-of-pocket expenses incurred while enrolled in college yield little or no financial return. This financial risk may discourage some people from taking out a loan and enrolling in college. Thus, even though prospective students do not appear to be credit constrained, a mechanism to share the college failure risk might improve social welfare and encourage more people to enroll for college. 1

The current operation of the student loan program suggests that is it administratively feasible to offer some insurance against college failure risk. Under the current system, a borrower can choose from a menu of fairly sophisticated repayment options (standard, graduated, incomecontingent and extended repayment). Nevertheless, under each of these payment options, the borrower is required to repay the entire loan and associated interest expenses regardless of whether he or she completed college..$^{2}$

\footnotetext{
${ }^{1}$ Given a dramatic shift against unskilled labor in the U.S. labor market between 1980-1990 (decline in wages, labor activity, longer unemployment spells for low skilled), Heckman (1999) has argued that increasing the supply of college labor can reverse this trend. Specifically, for 1990 workforce of 120 million, about 5.4 million would have to become college equivalents to reverse the 1980-1990 erosion of real wage, and about 1 million additional skilled persons would need to be added to the workforce each year on top of the once and for all change of 5.4 million.

${ }^{2}$ The borrower is permitted to default on the loan only if a repayment effort over 25 years does not fully cover all obligations.
} 
The objective of this paper is to study, theoretically and quantitatively, whether the student loan program can gainfully offer insurance against college failure risk. We conduct this analysis under two important constraints on the provision of this sort of insurance. First, we assume that any proposed insurance scheme cannot redistribute resources from people with high probability of completing college to people with low probability of completing college (and vice versa). Formally, this requires that the insurance program be self-financing with respect to each person who chooses to participate. The current programs enforce this selffinancing constraint regardless of whether the program participant actually graduates from college. In contrast, we permit dropouts to pay less than graduates but each participant pays the full cost of college in expectation. Second, we assume that the insurance program must guard against moral hazard, that is, the possibility that provision of insurance against college failure risk may increase the risk of failure. We derive conditions under which these constraints leave open the possibility of some insurance against college failure risk.

The quantitative section of the paper studies the impact of insurance against college failure risk on college enrollment decisions of individuals. We focus on the college enrollment decisions of individuals from low-income families - the ones for whom this sort of insurance is most relevant. These are individuals for whom the risk of college failure appears to be the highest currently. ${ }^{3}$ Furthermore, these are also the individuals for whom, conditional on dropping out of college, the burden of a student loans can be substantial. We find that for a plausibly calibrated model there is a large increase in ex-ante welfare from the optimal insurance program for college failure risk. Given existing estimates of the elasticity of college enrollment with respect to benefits of a college degree, we predict a large increase in college enrollment of individuals from low-income families.

\footnotetext{
${ }^{3}$ See Manski (1992) and Stinebrickner and Stinebrickner (2007)
} 


\section{Environment}

There are two periods indexed by $t=0,1$. There is a continuum of students indexed by ability $a \in[0,1]$. The distribution of ability in the population is given by the measure $F$. We think of $a$ as an observable signal of the probability of completing college (such as SAT scores) if the student puts in effort in college.

In period 0 students can enroll in college at the cost of $x>0$ units of a single consumption good. If the student puts in effort, which $\operatorname{costs} \gamma>0$ in utility terms, she can complete college in period 1 with probability $\pi(a)$ where $\pi(\cdot)$ is an increasing and continuous function of ability $a$ with $\pi(1)=1$ and $\pi(0)=0$. In case of completion the student receives endowment $y_{C}$ and in case of failure she receives $y_{N}<y_{C} 4$ We assume that if the student does not put in effort in college then she fails to graduate with probability one. 5 We will assume that effort in college is not observable to student loan administrators. 6

In addition to enrolling for college in period 0 , students have the choice of foregoing college and working. If they do so they suffer a disutility of effort in period 0 of $\theta>\gamma>0$ in utility terms and then earn $y_{N}$ in period 1. Thus, enrolling is college involves less effort (or more pleasant effort) than working in a low-paid paid job.

Students have (identical) preferences over the disutility of effort in period 0 and (potentially random) consumption in period 1 . These preferences are given by

$$
U(d, c)=-d+E u(c)
$$

where $u(c)$ is defined for all $c>0$, is strictly increasing and strictly concave and (at least)

\footnotetext{
${ }^{4}$ For simplicity we assume that post-completion earnings is a constant as is the earnings following failure. More generally we could let these outcomes be random.

${ }^{5}$ This captures the relevance of both ability and effort in school for the chance of success from college. This is consistent with empirical research that argues that SAT is a poor predictor for success post-college (Manski (1983)).

${ }^{6}$ Clearly this is a simplification because loan administrators have access to grades obtained in college. Making insurance conditional on grades will attenuate the moral hazard problem. However, as long as grades are not a perfect signal of effort, the moral hazard problem will remain.
} 
twice continuously differentiable. And $\lim _{c \rightarrow 0} u(c)=-\infty$ and $\lim _{c \rightarrow 0} u^{\prime}(c)=\infty$.

There is a social planner (student loan program administrator) who can borrow in the world capital market at the interest rate $r>0$ and can enforce intertemporal contracts at zero cost. We assume that $y_{C}-x(1+r)>y_{N}$ (college degree is profitable financial investment) and $x(1+r)<y_{N}$ (even dropouts can pay for college).

\section{College Enrollment and Failure Under the Current System}

As noted in the introduction under the current system any student wishing to enroll for college can obtain financing to do so. If they avail themselves of the financing, they will owe $x(1+r)$ in period 1.

Students in our model have the following choices in period 0 : they can work or enroll for college and, conditional on enrolling, they can choose to exert effort in college or not. The period-0 payoffs (utility) from these various choices are as follows. Working yields $W=-\theta+$ $\beta u\left(y_{N}\right)$, enrolling in college but shirking yields $S=\beta u\left(y_{N}-x(1+r)\right)$, and enrolling in college and making the effort yields $E(a)=-\gamma+\beta\left[\pi(a) u\left(y_{C}-x(1+r)\right)+(1-\pi(a)) u\left(y_{N}-x(1+r)\right)\right]$.

To proceed, we will make some assumptions about how these payoffs rank with respect to each other.

Assumption $1 E(1)-S>0$. When making the effort in college ensures completion with probability 1 then making the effort is strictly better than shirking.

Assumption $2 W-S>0$. Working is better than enrolling in college and shirking.

To determine who enrolls in college, we will first determine the set of students for whom, conditional on enrollment, making the effort in college is optimal. We have:

Proposition 3.1. Conditional on enrolling in college, there exists $a_{0} \in(0,1)$ such that expending effort is strictly preferred to shirking if and only if $a>a_{0}$. 
Proof. Consider the function $E(a)-S . E(0)-S=-\gamma<0$ and by Assumption 1, E(1) $-S>$ 0 . Since $E(a)$ is continuous and strictly increasing in $a$ it follows that there exists $a_{0} \in(0,1)$ such that $E\left(a_{0}\right)-S=0$. Clearly $E(a)-S>0$ if and only if $a>a_{0}$.

Next we have:

Proposition 3.2. There exists $a_{1} \in(0,1)$ such that enrolling in college is strictly optimal if and only if $a>a_{1}$. Furthermore, $a_{1}>a_{0}$.

Proof. By Assumption 2 we know that is better to work than to enroll and shirk in college. Therefore we need only consider the function $E(a)-W$ to determine who enrolls for college. Consider the value $E\left(a_{0}\right)-W$. We can write this as $\left[E\left(a_{0}\right)-S\right]-[W-S]$. By Proposition 3.1 the first term is 0 and by Assumption 2 the second term is strictly positive. Therefore $E\left(a_{0}\right)-W<0$. Next, consider the value $E(1)-W$ which is simply $\theta-\gamma+\beta\left[u\left(y_{C}-x(1+\right.\right.$ $\left.r))-u\left(y_{N}\right)\right]$. By assumption $\theta-\gamma>0$ and $\left.y_{C}-x(1+r)\right)>y_{N}$. Hence $E(1)-W>0$. Again, given the continuity and monotonicity of $E(a)$, there exists $a_{1} \in\left(a_{0}, 1\right)$ such that $E\left(a_{1}\right)-W=0$. Clearly $E(a)-W>0$ if and only if $a>a_{1}$.

Even though this model of college enrollment is very simple it sheds some light on the reasons why the college failure (dropout) rate is so high among low-income students. We can write $E(a)-W$ as the sum of three separate terms as follows:

$$
E(a)-W=[\theta-\gamma]+\pi \beta\left[u\left(y_{C}-x(1+r)\right)-u\left(y_{N}\right)\right]+(1-\pi) \beta\left[u\left(y_{N}-x(1+r)\right)-u\left(y_{N}\right)\right] .(2)
$$

The first term is the current net benefit of enrolling in college that stems from avoiding work in a low-paid unpleasant job. The second term is the expected future benefit of acquiring a college degree. The third is the expected future cost of failing to acquire a degree after having paid for it. For students with high $a$ (and therefore low $[1-\pi(a)]$ ) the expected cost of failure is negligible and enrolling in college is a "win-win" proposition: there is both a current and a future benefit from doing so. Thus, students continue to enroll for college 
until the expected future cost of failure is high enough to balance the current and future expected benefits. Assuming that low-income students are the marginal students, the model can plausibly explain why these students experience high dropout rates if current benefits from enrollment are high and discount factors are low.

\section{Insuring College Failure Risk}

Can the student loan program gainfully offer insurance against college failure risk? As noted in the introduction, we wish to answer this question recognizing that the student loan program cannot redistribute resources from observably high ability students (high $a$ ) to low ability students and recognizing that insurance against college failure may encourage shirking (and therefore failure).

It is best to break up the answer in two parts. Consider first the nature of insurance when loan administrators can observe effort so the moral hazard constraint is not an issue. Conditional on the student having put in effort, the student loan program gives a transfer $f_{a}$ to a student with ability $a$ if she fails college and a transfer $s_{a}$ if she completes college. Since the insurance is required to be self-financing (no cross-subsidies) we must have

$$
\pi(a) \cdot s_{a}+(1-\pi(a)) \cdot f_{a}=0
$$

Expected utility given these transfer is then

$$
\pi(a) \cdot u\left(y_{C}-x(1+r)-[(1-\pi(a)) / \pi(a)] f_{a}\right)+(1-\pi(a)) \cdot u\left(y_{N}-x(1+r)+f_{a}\right),
$$

where we have used equation (3) to express $s_{a}$ in terms of $f_{a}$. Maximizing the above expression with respect to $f_{a}$ yields the following first-order condition:

$$
-u^{\prime}\left(y_{C}-x(1+r)-[(1-\pi(a)) / \pi(a)] f_{a}\right)+u^{\prime}\left(y_{N}-x(1+r)+f_{a}\right)=0 .
$$

Hence the value of $f_{a}$ that attains the maximum is $f_{a}^{*}=\left(y_{C}-y_{N}\right) \pi(a)$ and the implied optimal value of $s_{a}$ is $s_{a}^{*}=\left(y_{C}-y_{N}\right)(1-\pi(a))$. At these values the marginal utility following 
failure and success are equalized. Because there is no uncertainty in earnings following success or failure in college, the optimal values of $f_{a}$ and $s_{a}$ also stabilize consumption and therefore total utility.

The stabilization of total utility means that if effort is not observable to the loan administrator, this sort of insurance cannot be offered. It is easy to check that with this insurance in place $E(a)-S=-\gamma+\beta \pi(a)\left[u\left(y_{C}-x(1+r)-s_{a}^{*}\right)-u\left(y_{N}-x(1+r)+f_{a}^{*}\right)\right]$ is simply $-\gamma$. Therefore every college student will have a strict incentive to shirk. Since failure will happen with probability one the resource balance condition (3) will be violated.

From this discussion it is evident that when effort is not observable, the best insurance scheme that can be offered to a student with ability $a$ is given by the solution to the following problem:

$$
\begin{aligned}
& \max _{f_{a}} \pi(a) u\left(y_{C}-x(1+r)-[(1-\pi(a)) / \pi(a)] f_{a}\right)+(1-\pi(a)) u\left(y_{N}-x(1+r)+f_{a}\right) \\
& \text { s.t. } \\
& -\gamma+\beta \pi(a)\left[u\left(y_{C}-x(1+r)-[(1-\pi(a)) / \pi(a)] f_{a}\right)-u\left(y_{N}-x(1+r)+f_{a}\right)\right] \geq 0
\end{aligned}
$$

This problem incorporates the "no shirking" constraint, $E(a)-S \geq 0$, as an additional constraint. The self-financing constraint is incorporated directly in the objective function and the "no-shirking" constraint. We have the following:

Proposition 4.1. Insurance is offered only to students with $a>a_{0}$. For any student to whom insurance is offered $f_{a}$ is chosen to make the "no-shirking" constraint hold exactly.

Proof. By Proposition 3.1, $E(a)-S$ evaluated at $f_{a}=0$ is strictly positive for all $a>a_{0}$. Furthermore, we can verify that the derivative of the objective function with respect to $f_{a}$ is strictly positive at $f_{a}=0$. Therefore it is optimal to increase $f_{a}$ marginally from 0 . As $f_{a}$ increases the term $\left[u\left(y_{C}-x(1+r)-[(1-\pi(a)) / \pi(a)] f_{a}\right)-u\left(y_{N}-x(1+r)+f_{a}\right)\right]$ decreases and $E(a)-S$ declines toward 0 . Since the derivative of the objective function (with respect to $f_{a}$ ) 
remains strictly positive as long as $\left.f_{a}<\pi(a)\left(y_{C}-y_{N}\right)\right)$ and $E(a)-S$ declines monotonically toward $-\gamma$ as $f_{a}$ approaches $\left.\pi(a)\left(y_{C}-y_{N}\right)\right)$ it follows that $E(a)-S$ will reach 0 before all gains from insurance are exhausted. Hence the optimal $f_{a}$ is one that sets $E(a)-S=0$.

Because the optimal $f_{a}$ is simply determined by the equation $E(a)-S=0$ it is relatively easy to characterize its behavior. We have

Proposition 4.2. The indemnity offered in case of college failure is increasing in a.

Proof. Holding fixed $f_{a},-\gamma+\beta \pi(a)\left[u\left(y_{C}-x(1+r)-[(1-\pi(a)) / \pi(a)] f_{a}\right)-u\left(y_{N}-x(1+r)+f_{a}\right)\right]$ is increasing in $a$ since $\pi(a)$ is increasing in $a$ and $[(1-\pi(a)) / \pi(a)]$ is decreasing in $a$. Furthermore, the range of $f_{a}$ values for which the derivative of the objective function with respect to $f_{a}$ is positive is also increasing in $a$ since $\pi(a)\left[y_{C}-y_{N}\right]$ is increasing in $a$. Therefore it is optimal and feasible to increase $f_{a}$ as $a$ increases.

It is not possible to characterize $s_{a}$ without further assumptions because there are offsetting effects: $s_{a}$ will tend to increase in $a$ because $f_{a}$ is increasing in $a$ but since failure is less likely with higher $a, s_{a}$ will tend to decrease with $a$. Simulations indicate that $s_{a}$ first rises with $a$ and then declines.

How does the provision of optimal insurance affect enrollment decisions? We have the following result:

Proposition 4.3. Let $f_{a}^{*}$ be the solution to the insurance problem subject to the "no shirking" and self-financing constraints. With this insurance in place, there exists $a_{m} \in\left(a_{0}, a_{1}\right)$ such that enrolling in college is strictly optimal if and only if $a>a_{m}$.

Proof. The first step is to establish that given $f_{a}^{*}$ the expression $E\left(a ; f_{a}^{*}\right)-W$ (the difference between the payoffs from enrolling in college and making effort and the payoff from working) is strictly increasing in $a \in\left(a_{0}, 1\right]$. We can write $E\left(a ; f_{a}^{*}\right)-W$ as $\left[E\left(a ; f_{a}^{*}\right)-S\left(f_{a}^{*}\right)\right]+\left[S\left(f_{a}^{*}\right)-\right.$ $W]$. Under optimal insurance, $\left[E\left(a ; f_{a}^{*}\right)-S\left(f_{a}^{*}\right)\right]=0$ by Proposition 4.1. By Proposition 
4.2, $\left[S\left(f_{a}^{*}\right)-W\right]=\theta+\beta\left[u\left(y_{N}-x(1+r)+f_{a}^{*}\right)-U\left(y_{N}\right)\right]$ is increasing in $a$. Next, observe that without insurance $E\left(a_{1}\right)-W=0$ (Proposition 3.2). Since insurance increases the expected utility from enrolling in college it follows that $E\left(a_{1} ; f_{a}^{*}\right)-W>0$. Next, observe that by Proposition 4.2, $f_{a_{0}}^{*}=0$. Therefore, $E\left(a_{0} ; f_{a_{0}}^{*}\right)-W=E\left(a_{0}\right)-W$. But we know (Proposition 3.1) $E\left(a_{0}\right)-W<0$. Therefore, $E\left(a_{0} ; f_{a_{0}}^{*}\right)-W<0$. Since $E\left(a ; f_{a}^{*}\right)-W$ is continuous and strictly increasing there must exist $a_{m} \in\left(a_{0}, a_{1}\right)$ such that $E\left(a ; f_{a_{m}}^{*}\right)-W=0$. Evidently students will enroll in college if and only if $a>a_{m}$.

One interesting implication of the result that $a_{m}<a_{1}$ is that the average failure rate in the presence of optimal insurance is higher. This is true because failure rates for students who are induced to enroll in college because of insurance are higher than the failure rate of the marginal student when there is no insurance. Every one who enrolls in college puts in effort - the increase in average failure rate is a pure composition effect. The higher average failure rate is also consistent with higher welfare.

There are two additional points worth noting. First, the assumption that outcomes following success or failure in college is perfectly known (i.e., $y_{c}$ and $y_{N}$ are known numbers) is a potentially important simplification. It means that providing insurance against college failure also provides insurance against all earnings certainty. It would be preferable to explicitly account for uncertainty in earnings following graduation or failure. One case with earnings uncertainty that can be analyzed along almost the same lines as above is if $u(c)=b \exp (-\alpha c)$. In this case, marginal utility is proportional to total utility for each consumption $c$. Because of this proportional relationship, stabilizing the expected marginal utility of consumption across success and failure (which is what failure insurance would aim to do) will also stabilize expected total utility across success and failure. This means that full insurance against college failure risk will violate the "no-shirking" constraint exactly as it did in the case where $y_{C}$ and $y_{N}$ are non-random. Consequently, optimal insurance will involve making $f_{a}$ low enough so that the "no-shirking" constraint exactly binds. However, outside of the exponential utility case, it is unclear what stabilizing expected marginal utilities means for 
expected total utilities. In particular, for general utility functions and general probability distributions of earnings following success and failure, full actuarially fair insurance against college failure risk need not necessarily eliminate the incentive to exert effort in college.

Second, optimal insurance involves (for the most part) forgiving some portion of the student loan following failure: that is one interpretation of the term $\left[-x(1+r)+f_{a}^{*}\right]$. However when the probability of successfully completing college is close to 1 , the term $\left[-x(1+r)+f_{a}^{*}\right]$ can be negative. In other words, not only is the student's loan completely forgiven in event of failure, she receives a transfer as well. This possibility is most easily seen in the case where effort is observable and therefore the "no-shirking" constraint can be ignored. In this case $f_{a}^{*}=\pi(a)\left(y_{N}-y_{C}\right)$. When $\pi(a)$ is close to 1 this value is close to $\left(y_{N}-y_{C}\right)$ which (by assumption) is greater than $x(1+r)$. Hence $\left[-x(1+r)+f_{a}^{*}\right]<0$. This result may seem problematic from an administrative point of view and it may be desirable to impose the further constraint that $\left[-x(1+r)+f_{a}^{*}\right] \geq 0$ when determining the optimal insurance scheme.

\section{Quantitative analysis}

The quantitative questions we address in this section are what is the benefit from having the government student loan program in place? What are the effects from offering insurance against the riskiness of college education on college enrollment and failure risk? We also quantify how close the actual scheme is to the optimal insurance scheme.

\subsection{Parametrization}

We consider a finite number of types on the ability set $[0,1]$ with the probability of graduating from college given by a linear function. With the assumptions that $\pi(0)=0$ and $\pi(1)=1$, this will be given by $\pi(a)=a$.

The utility function is CRRA with coefficient $\sigma$. We calibrate the benchmark model (Section 3) to the U.S. economy. We calibrate the distribution of ability to the SAT scores of all students in a senior year in 1999 in the U.S. The mean is 1016 and standard deviation 
Table 1: Parameter Values

\begin{tabular}{|c|c|c|c|}
\hline Parameter & Name & Value & Target/Source \\
\hline \hline$\sigma$ & Coef of risk aversion & 2 & standard \\
\hline$r$ & Risk free rate & 0.05 & avg rate in 1990 \\
\hline$y_{N}^{*}$ & Low state outcome & 1 & avg earnings HS graduates/ PSID \\
\hline$y_{C}$ & High state outcome & 1.13 & avg earnings college graduates/ PSID \\
\hline$x$ & College debt & 0.083 & college cost/ College Board \\
\hline$\gamma$ & Dis-utility in college & 0.01 & forgone opportunity during college \\
\hline$\theta$ & Dis-utility in the low paid job & 0.043 & college enrollment \\
\hline
\end{tabular}

* Normalized.

226 (College Board 2007). In our model, this translates to 0.51 for the mean and 0.18 for the standard deviation. Parameters of the model are given in Table 1.

The outcomes in the low and high states are given by $y_{N}=1$ and $y_{C}=1.13$. In our model, $y_{C} / y_{N}$ represents the earnings premium for an individual that completes college, relative to the same individual in the counterfactual situation of not attending college. This cannot be directly mapped into the rates of return for college education obtained from standard Mincer regressions, since these rates do not typically correct for the ability bias implied by the selection of individuals between college and non-college choices. Willis and Rosen (1979), adjusting for selection in ability, find a lifetime rate of return of attending college of $9.9 \%$ per year. Later research estimates the rate of return on college to be between $8 \%$ and $13 \%$ per year (see Willis (1986) and Card (2001)). This high return to college education also implies very large differences in lifetime income. We use the $13 \%$ rate of return per year, which is consistent with the estimates for a lifetime college premium of 1.58 in Murphy and Welch (1992). ${ }^{7}$ The average earnings for college graduates are $\$ 42000$ (1999 constant dollars). The low outcome is normalized to 1.

The loan amount is set to $x=0.083$. In our model, the loan amount that the government collects is computed as the fixed payment for a console with the discounted present value that equals the weighted average college cost for private and public institutions. The cost

\footnotetext{
${ }^{7}$ Restuccia and Urrutia (2004) use the $10 \%$ rate of return that corresponds to a lifetime college premium of 1.5 .
} 
for college is $\$ 20706 /$ year for private universities and $\$ 8275 /$ year for public universities in 1999. Among the students who borrowed for their education, $67 \%$ went to public and $33 \%$ to private universities. The enrollment-weighted average cost is $\$ 49508$ in constant 1999 dollars (College Board (2001)). Beyond the explicit cost of college, the opportunity cost of forgone earnings is large, at approximately $\$ 17,000$ (1999 constant dollars) per full-time student annually in the U.S. In our model the dis-utility in college parameter, $\gamma$ captures the utility loss of forgone earnings from attending college. We estimate it to $\gamma=0.01$.

The last parameter, $\theta$, dis-utility from effort in the low paid job is calibrated to match college enrollment in the U.S. with the corresponding endogenous variable in the model. The college enrollment rate in 1999 is $63 \%$.

\subsection{Results}

In the benchmark economy, the model delivers a college completion rate of $61.6 \%$. In data the college completion rate in 1999 is $58 \%$ (NCES (2004). Of everyone who enrolled in college in 1999, 42\% did not earn a college degree by the end of the next 5 years. We first present the optimal arrangements for the case effort in college is observable and for the case it is not. We then quantify the effects of the government insurance program on college enrollment, dropout rate and welfare.

\subsubsection{Observable Effort}

In the case when effort during college is observable, the optimal schedule $\left(f_{a}, s_{a}\right)$ is graphed in Figure 1. The best the planner can do in case failure occurs is to forgive the agent from his full debt (the constraint on transfer $f_{a}^{*}$ is imposed here). This is optimal for high ability individuals for whom the risk of failure is low. When the ability level declines, the planner will require the agent to partially pay for his college loan in case he fails to graduate. Higher the risk, more the agent is required to pay towards his college loan, $f_{a}$ declines as $a$ declines. Given that the planner imposes a self-financing scheme for each person, he sets the 


\section{Figure 1: Optimal transfers without moral hazard}

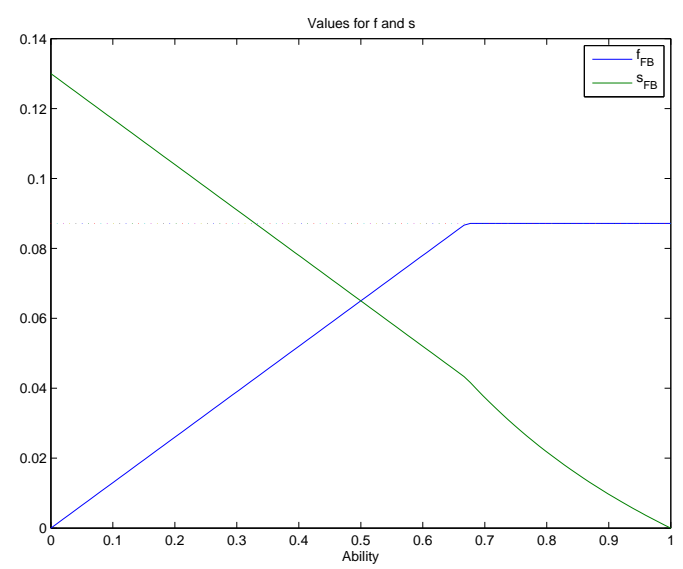

premium in the successful state, $s_{a}$, to cover in expectation the positive transfer he delivers in the unsuccessful state. For high ability levels, failure is not that likely so the insurance premium, $s_{a}$, is small. If the ability level declines, failure is more likely to occur and the premium the agent has to pay increases. Out of college students, $27.5 \%$ will be fully forgiven of their loans in the case they fail to graduate from college.

\subsubsection{Unobservable Effort}

In the case the effort choice during college is not observable to the planner, the optimal solution suggests, as before, an increasing schedule in ability levels for the transfer in case of failure, $f_{a}$. Note, however, in Figure 2, that in order to prevent shirking in college, the penalty for the unsuccessful state is larger for all ability levels. Fewer high ability individuals are fully exempt of their debt. Lower ability individuals do not only pay more towards their college loans, but they might be required to also pay a premium in case they fail. A second important note is that the insurance premium the agent has to pay in case of success is a decreasing schedule in ability only for medium and high ability levels. Low ability agents get a transfer in the successful state and pay a premium in the failure state given that for these groups the moral hazard problem is more severe. Under this scenario, only $13.3 \%$ of college students will be forgiven of their loans. 


\section{Figure 2: Optimal transfers under moral hazard}

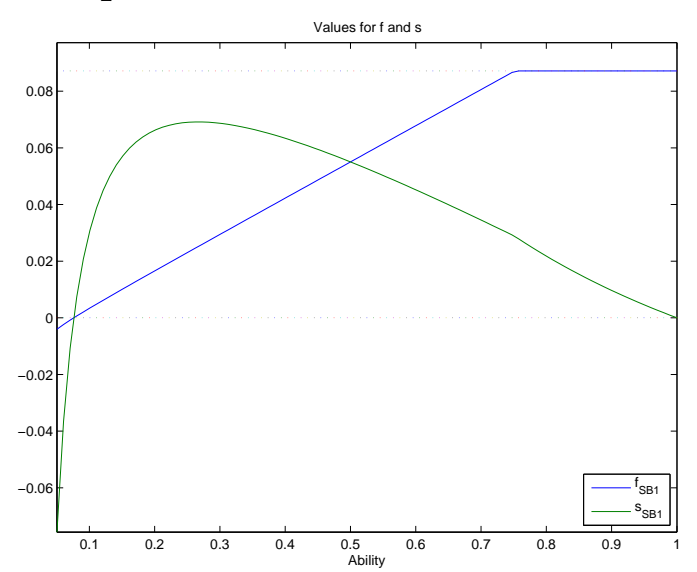

\subsubsection{The Effects on College Enrollment, College Failure, and Welfare}

In order to study the benefit of having the loan program in place, we compare the insurance scheme under the moral hazard environment to the benchmark case where no government insurance scheme is provided. We obtain an increase of $4 \%$ in the college enrollment rate and a decline from $61.6 \%$ to $40.5 \%$ in the college completion rate. There is higher failure risk on average given that the insurance scheme will attract lower ability individuals to college.

We turn next to the welfare implications of the loan program. For welfare measurement we use aggregate total welfare with agents equally weighted. With $W_{M H}$ denoting total welfare in the case the government provides insurance and effort is not observable, and $W_{N o G}$ denoting total welfare under the case there is no government insurance, we quantify $\mu=\frac{W_{M H}-W_{N o G}}{\left|W_{N o G}\right|}$. Thus $\mu>0$ implies a welfare gain from the government program, otherwise the reverse is true. These measures are given below by:

$$
\begin{aligned}
W_{M H} & =\int_{0}^{a_{m}}\left[-\theta+\beta u\left(y_{N}\right)\right] d F+ \\
& +\int_{a_{m}}^{1}\left[-\gamma+\beta\left[\pi(a) u\left(y_{C}-x(1+r)-s_{a}^{*}\right)+[1-\pi(a)] u\left(y_{N}-x(1+r)+f_{a}^{*}\right)\right]\right] d F
\end{aligned}
$$




$$
\begin{aligned}
W_{N o G} & =\int_{0}^{a_{1}}\left[-\theta+\beta u\left(y_{N}\right)\right] d F+ \\
& +\int_{a^{\prime} 1}^{a_{m}}\left[-\gamma+\beta\left[\pi(a) u\left(y_{C}-x(1+r)\right)+[1-\pi(a)] u\left(y_{N}-x(1+r)\right)\right]\right] d F
\end{aligned}
$$

with $a_{m}$ and $a_{1}$, the thresholds to enroll in college in the case insurance under moral hazard is provided and no insurance is available.

The program is beneficial on welfare grounds. Total welfare under insurance with moral hazard increases by $0.237 \%$ relative to the case when there is no insurance. The average welfare gain per college graduate is $0.224 \%$. The program gainfully insures against college risk, it narrows the gap between no insurance and optimal insurance under no moral hazard by $97 \%$. When effort is observable total welfare is $0.242 \%$ higher relative to no insurance and the average welfare per college graduate $0.231 \%$ higher.

\section{Conclusion}

We have developed a theoretical framework that studies whether the student loan program can gainfully offer insurance against college failure risk. We conduct the analysis under two important constraints on the provision of this sort of insurance. First, we assume that any proposed insurance scheme cannot redistribute resources from people with high probability of completing college to people with low probability of completing college. The government loan program does not permit students with superior post-college labor market outcomes to partially pay the college expenses of students with poor post-college labor market outcomes. Second, we assume that the insurance program must guard against moral hazard, that is, the possibility that provision of insurance against college failure risk may increase the risk of failure.

We argue that such an insurance scheme is administratively feasible and provide conditions 
under which these constraints leave open the possibility of some insurance against college failure risk. We show that the provision of such insurance increases college enrollment, college failure rate, and average welfare. We calibrate the model to US data on college costs, enrollment rates, college premium, and average indebtedness of program participants and quantify the effects on college enrollment and dropout rates. We find that offering insurance against college failure risk raises enrollment rates by 4 percent, decreases college completion rate from 61 percent to 40 percent and increases welfare by about 0.24 percent.

\section{References}

Akyol, A., And K. Athreya (2005): "Risky Higher Education and Subsidies," Journal of Economic Dynamics and Control, 29(6), 979-1023.

Cameron, S., and C. Taber (2001): "Borrowing Constraints And the Returns to Schooling," NBER working paper.

Card, D. (2001): "Estimating the Return to Schooling: Progress on Some Persistent Econometric Problems," Econometrica, 69(5), 1127-1160.

Carneiro, P., and J. Heckman (2002): "The Evidence on Credit Contraints in Post Secondary Schooling," The Economic Journal.

CollegeBoard (2001): "Trends in College Pricing," .

— (2007): "College Bound Seniors: Total Group Profile Report," .

Heckman, J. (1999): "Doing it Right: Job Training and Education," Public Interest, 135, 86.

Ionescu, F. (2007): "Federal Student Loan Program: Quantitative Implications for College Enrollment and Default Rates," Working paper. 
L. Berkner, S. H., and E. F. Cataldi (2002): "Descriptive Summary of 1995-96 Beginning Postsecondary Students: Six Years Later," National Center for Education Statistics 2003151.

M. Amador, I. W., and G. Angeletos (2006): "Commitement vs Flexibility," Econometrica, 74(2), 365-396.

Manski, C. (1983): "College Choice in America," Harvard University Press, 79 Garden Street, Cambridge, MA 02138-9983.

— (1992): "Parental Income and College Opportunity. DSC Report Series," .

Murphy, K., And F. Welch (1992): "The structure of wages," The Quarterly Journal of Economics, 107, 285-386.

NCES (2004): "The Condition of Education 2004 ,"Washington, DC: U.S. Government Printing Office, (077), U.S. Department of Education.

Restuccia, D., and C. UrRutia (2004): "Intergenerational Persistence of Earnings: The Role of Early and College Education," The American Economic Review, 94(5), 1354-1378.

Stinebrickner, T., and R. Stinebrickner (2007): "The Effect of Credit Constraints on the College Drop-Out Decision A Direct Approach Using a New Panel Study," NBER Working paper.

Willis, R. (1986): "Wage Determinants," Ashenfelter, O. and Layard, R., Handbook of Labor Economics, North Holland, Amsterdam.

Willis, R., and S. Rosen (1979): "HEducation and Self-Selection," Journal of Political Economy, 87(5), 7-36. 